\title{
An agricultural analysis of rainfall reliability for Cameroon
}

\author{
H. J. W. Mutsaers
}

ENSA, University of Yaoundè, B.P. 138, Yaoundè, Cameroon ${ }^{1}$

Accepted: 19 September 1978

Key words: rainfall, analysis

\section{Summary}

An improvement of Manning's analysis of rainfall reliability is presented. Confidence limits of 20-day rainfall totals are calculated with a simple normalizing transformation. Rainfall distribution within a 20-day period is assessed by simply counting the frequency of occurence of dry spells exceeding 10 days duration. The joint probability of deficient 20-day rainfall total and dry spell occurence is estimated. The analysis is applied to two practical examples in Cameroon.

\section{Introduction}

Analyses of rainfall for agricultural purposes are fairly rare. The available analyses are either too general as with work done by geographers, or the statistical techniques are too sophisticated for the general user (e.g. Smith \& Schreiber, 1973, 1974).

H. L. Manning developed a fairly simple method for the assessment of rainfall frequencies from an agricultural viewpoint two decades ago (Manning, 1950, 1956). As a first analysis he calculated confidence limits for yearly or seasonal rainfall. In most climates these totals will be practically normally distributed.

As a more detailed analysis Manning proposed a normalizing transformation of 20-day totals and calculated confidence limits for each period. There are two objections to the latter approach.

- The transformation parameters are calculated from all 20-days periods lumped together. The shape of the probability distributions, however, will vary over a year and especially beginning and end of the rainy season will suffer from this inaccuracy.

- 20-day totals may give a false impression of the adequacy of water availability to crops when rain falls in heavy showers interrupted by long dry spells.

The present study, with Cameroon data, attempts an improvement of Manning's approach to overcome its shortcomings.

1 Present address: Department Tropical Crops, Agricultural University, Wageningen. the Netherlands. 
An agriculturally useful analysis should consider both the amount and the distribution of rainfall over the periods under study. The present analysis therefore considers the following aspects.

- Confidence limits for seasonal or yearly rainfall totals as a first assessment of rainfall reliability.

- Confidence intervals of rainfall totals over successive, short periods in order to assess the risk of deficient rainfall amounts in each period. Ten-day totals seem the most attractive but their distribution is often extremely skew and beginning and end of he rainy season are difficult to handle because of many years with zero rainfall. In accordance with Manning 20-day periods, overlapping by 10 days, were chosen.

- Even within relatively short periods the rainfall distribution may be of major importance for crops with a particularly drought-sensitive period (e.g. maize at tasseling) and for any crop just after sowing. This within-period distribution is reflected in the occurence of dry spells starting in a given period. A dry spell is defined here as a spell of more than 10 days duration with an average daily rainfall below some threshold value. These dry spell occurences are simply represented as frequencies of dry spells starting in a given period and no attempt was made to work out their statistics.

\section{Material and methods}

Daily rainfall figures up to 1973 for a large number of meteorological stations in Cameroon are available on magnetic tape. ${ }^{1}$ As these data are the original observations they had to be evaluated for systematic errors. This was done by the double mass technique (e.g. Searcy \& Hardison, 1960) as follows.

- All incomplete monthly records were discarded.

- All suspicious looking data were discarded using the comments supplied by ORSTOM with the raw data.

- A double mass analysis was then done using groups of at least 3, but in most cases 4 or 5 , more or less adjoining stations. Stations included in a group conformed to the same pattern of yearly rainfall distribution. Systematic changes in the record of a station were corrected by a simple multiplication factor on the daily observations. The longest period without a systematic change was already used as a basis for this correction, with preference for more recent periods in case of doubt. The following analyses were executed for 17 stations scattered over the country. Results for 3 of these from two widely different rainfall regimes will be discussed in this article. Average monthly rainfall data for these stations are given for reference in Table 1.

The two climatic regions may be characterized as follows:

- Center South Province (Yaoundé). A monsoon climate with a bimodal rainfall distribution. The long dry season covers approximately 4 months.

1 Purchased from Service Hydrologique, ORSTOM, Paris, by permission of the Comité Interafricain d'Etudes Hydrauliques, B.P. 369, Ouagadougou, Haute Volta. 
Table. 1. Average monthly rainfall $(\mathrm{mm})$ for 3 Cameroon meteorological stations. 1

\begin{tabular}{lccc}
\hline Month & $\begin{array}{l}\text { Yaoundé (Aéréo) } \\
\text { (Center South) }\end{array}$ & $\begin{array}{l}\text { Guider } \\
\text { (North) }\end{array}$ & $\begin{array}{l}\text { Maroua (Agro) } \\
\text { (North) }\end{array}$ \\
Jan & 23.1 & 0.0 & 0.0 \\
Feb & 62.5 & 0.5 & 0.1 \\
Mar & 150.0 & 4.4 & 1.3 \\
Apr & 193.5 & 30.9 & 14.2 \\
May & 216.6 & 100.8 & 58.2 \\
Jun & 155.0 & 133.9 & 110.3 \\
Jul & 62.3 & 187.7 & 197.3 \\
Aug & 85.3 & 243.4 & 257.4 \\
Sep & 239.2 & 170.1 & 142.4 \\
Oct & 303.2 & 61.3 & 26.9 \\
Nov & 125.7 & 3.2 & 0.3 \\
Dec & 26.4 & 0.0 & 0.0 \\
Total & 1642.8 & 936.2 & 808.6 \\
\hline
\end{tabular}

1 Yaoundé: lat.: $3^{\circ} 50^{\prime} 24^{\prime \prime} \mathrm{N}$; long.: $11^{\circ} 31^{\prime} 37^{\prime \prime} \mathrm{E}$; alt.: $760 \mathrm{~m}$; observation period: 31 years. Guider: lat.: $9^{\circ} 56^{\prime} \mathrm{N}$; long.: $13^{\circ} 57^{\prime} \mathrm{E}$; alt: $356 \mathrm{~m}$; observation period: $35 / 39$ years. Maroua: lat.: $10^{\circ} 35^{\prime} \mathrm{N}$; long.: $14^{\circ} 18^{\prime} \mathrm{E}$; alt.: $402 \mathrm{~m}$; observation period: $22 / 25$ years.

- North Province (Guider and Maroua). A savanna climate. Rainfall shows a single peak and the dry season is long and pronounced.

\section{Analysis}

Transformation of 20-day totals

For each station the year was split up into 36 overlapping periods: 1-20 January, 11-31 January, 21 January - 10 February, etc. Thus each period covers approximately 20 days.

It appears safe to assume that the shape of the distribution of 20-day totals will change gradually over successive overlapping periods. The shape parameter 'skewness' as calculated from relatively small samples (most reliable records cover around 25-30 years) only gives very rough estimates. If, however, we accept a seasonal pattern for this parameter, we may fit a smoothed curve, thus correcting the estimate for any one period by that of the adjoining periods. This should greatly improve these estimates. Similar reasoning suggests the following normalizing transformation procedure.

By means of a simple trial and error algorithm by computer, different powers were applied to the 20 -day totals until skewness became zero. The powers at which skewness became zero were smoothed by the parabolic arc estimation method (Langbein, 1960). The resulting pattern is presented for three stations in Fig. 1.

Actually calculated best powers are given in the figure for Yaoundé together with the smoothed curve as an example. Skewness of some of the 20-day totals was little sensitive to transformation. The algorithm in those cases produced extreme values for best power of below zero or far exceeding unity. Those values 
were set to 0.10 or 1.00 and are encircled in Fig. 1a. (Another quick method of power transformation is given by Hinkley, 1977.)

A complication is introduced by the high frequency of zeros at the beginning and end of the rainy season. As 20-day periods having an average rainfall of less than $10 \mathrm{~mm}$ are of little agricultural interest anyway, it was decided to disregard those.
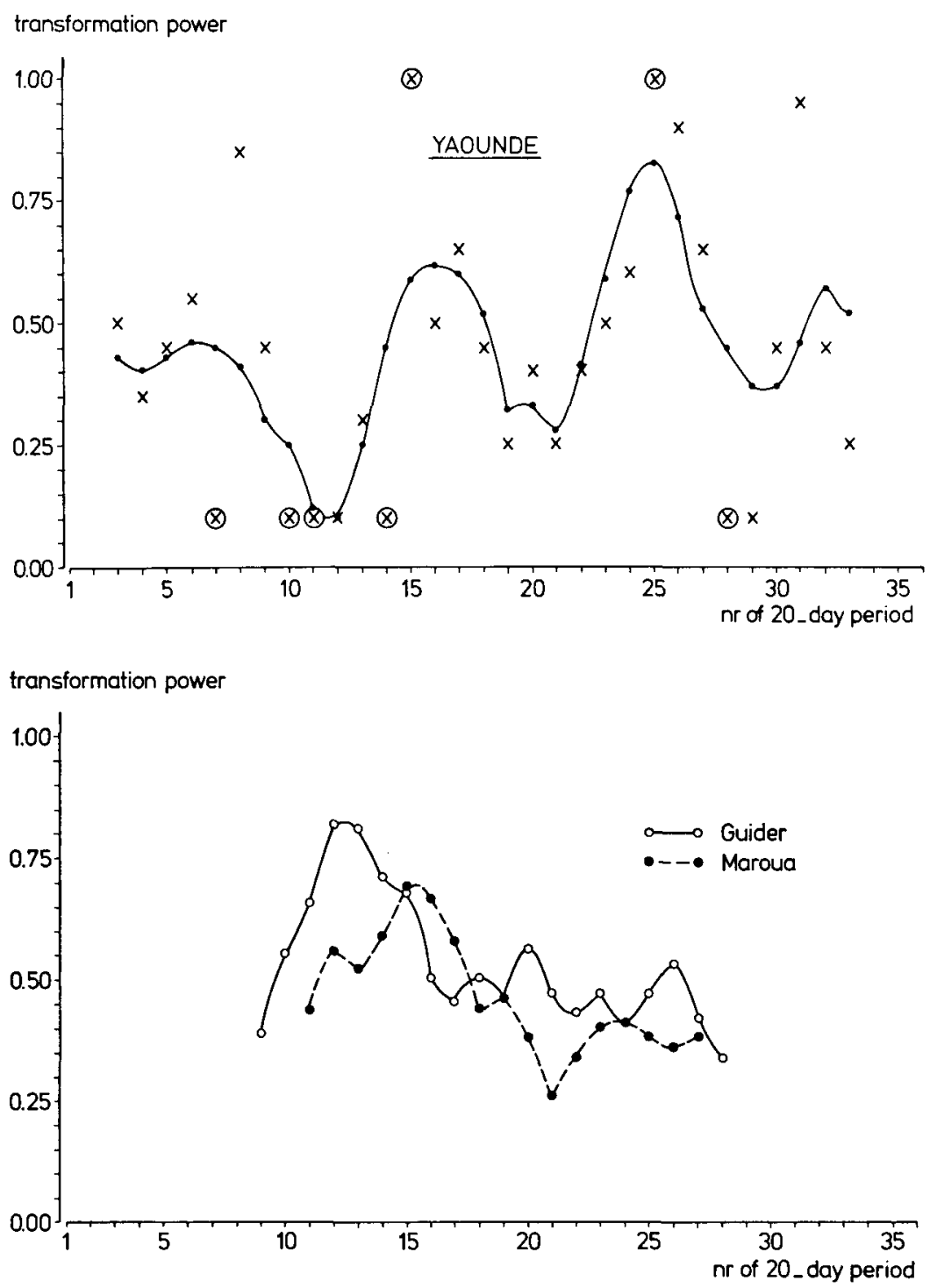

Fig. 1. Smoothed best powers for transformation of 20-day rainfall totals. a (top): Yaoundé; b (bottom): Guider, Maroua. 
rainfall in $\mathrm{mm}$

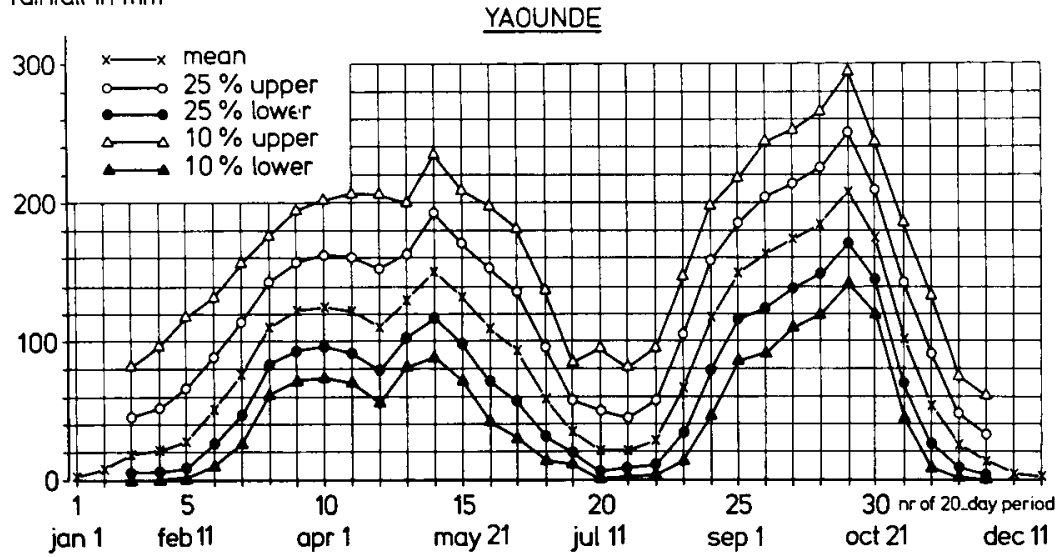

rainfall in $\mathrm{mm}$

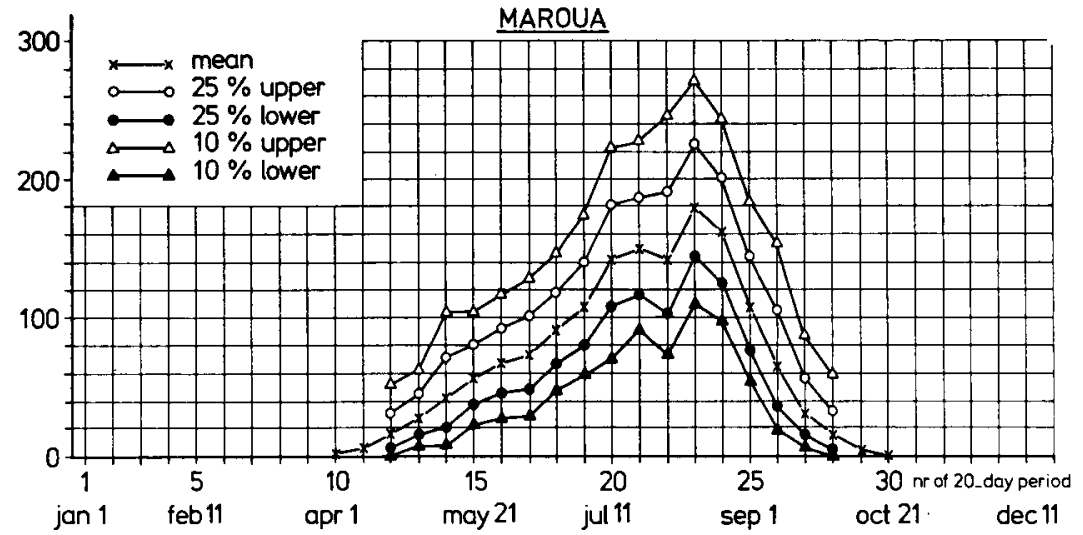

rainfall in $\mathrm{mm}$

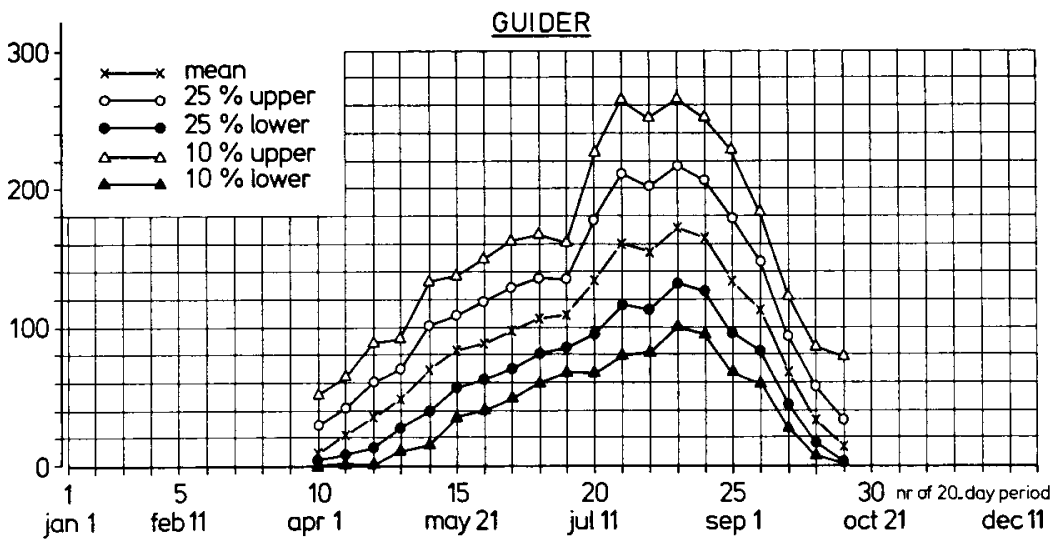

Fig. 2. Means and confidence limits of 20-day rainfall totals. a (top): Yaoundé; b (middle): Maroua; c (bottom): Guider.

Neth. J. agric. Sci. 27 (1979) 
The values of skewness and kurtosis of the remaining transformed variables, calculated from the smoothed transformation powers, always remained below the $5 \%$ limit of significant departure from normality (see Snedecor \& Cochran, 1967). For each 20-day period mean, variance and confidence limits for individual observations were calculated at two levels of probability: $50 \%$ and $20 \%$. This corresponds to a probability of $25 \%$ and $10 \%$ below the lower confidence limit. The expression used for calculating these limits is as follows:

$$
\begin{aligned}
& \lim _{\mathrm{P}}=\overline{\mathrm{x}} \pm \mathrm{t}_{(\mathrm{n}-1) \mathrm{P}} \mathrm{S}_{\mathrm{x}}\left(1+\frac{1}{\mathrm{n}}\right)^{\frac{1}{2}} \\
& \text { with } \begin{aligned}
\mathrm{P} & =\text { probability level } \\
\overline{\mathrm{x}} & =\text { mean of transformed } 20 \text {-day total } \\
\mathrm{n} & =\text { number of observations } \\
\mathrm{t} & =\text { percentage point of } \mathrm{t} \text { distribution }
\end{aligned}
\end{aligned}
$$

Next, the mean and confidence limits were transformed back to the orginal scale. Confidence limits for 3 stations are presented in Fig. 2.

A $\chi^{2}$ test was done to test whether the real number of observations outside and inside the limits (cumulated for all 20-day periods) corresponded with the pre-

\begin{tabular}{|c|c|c|c|c|c|c|c|c|c|}
\hline \multirow[t]{3}{*}{ Station } & \multirow{3}{*}{$\begin{array}{l}\text { Number of } \\
\text { observations }\end{array}$} & \multicolumn{4}{|l|}{$25 \%$} & \multicolumn{4}{|l|}{$10 \%$} \\
\hline & & \multirow[t]{2}{*}{ expected } & \multicolumn{2}{|c|}{ observed } & \multirow[t]{2}{*}{$x^{2}$} & \multicolumn{3}{|c|}{ expected observed } & \multirow[t]{2}{*}{$x^{2}$} \\
\hline & & & upper & lower & & & upper & lower & \\
\hline Akonolinga & 686 & 172 & 173 & 175 & 0.16 & 69 & 70 & 64 & 0.36 \\
\hline Bafoussam & 745 & 186 & 174 & 181 & 1.78 & 75 & 68 & 65 & 2.21 \\
\hline Bertoua & 986 & 247 & 246 & 248 & 0.01 & 99 & 95 & 100 & 0.16 \\
\hline Bétaré Oya & 765 & 191 & 184 & 197 & 0.45 & 77 & 74 & 79 & 0.16 \\
\hline Dschang & 736 & 184 & 180 & 166 & 3.16 & 74 & 73 & 69 & 0.34 \\
\hline Ebolowa & 1242 & 311 & 293 & 295 & 3.51 & 124 & 107 & 118 & 3.24 \\
\hline Garoua & 630 & 158 & 167 & 154 & 0.77 & 63 & 62 & 62 & 0.04 \\
\hline Guider & 496 & 124 & 126 & 122 & 0.06 & 50 & 39 & 51 & 2.52 \\
\hline Maroua & 419 & 105 & 103 & 104 & 0.06 & 42 & 39 & 34 & 2.04 \\
\hline Mora & 354 & 89 & 90 & 93 & 0.46 & 35 & 27 & 24 & 7.05 \\
\hline Nanga Eboko & 918 & 230 & 232 & 218 & 0.78 & 92 & 86 & 93 & 0.41 \\
\hline Ndikinimeki & 594 & 149 & 134 & 145 & 2.59 & 59 & 52 & 53 & 2.01 \\
\hline Ngaoundéré & 726 & 182 & 188 & 185 & 0.58 & 73 & 65 & 67 & 1.53 \\
\hline Tibati & 643 & 161 & 159 & 168 & 0.44 & 64 & 52 & 64 & 2.66 \\
\hline Sangmelima & 1039 & 260 & 251 & 263 & 0.39 & 104 & 98 & 95 & 1.36 \\
\hline Yagoua & 385 & 96 & 92 & 92 & 0.75 & 39 & 36 & 33 & 1.16 \\
\hline Yaoundé & 864 & 216 & 208 & 216 & 0.44 & 86 & 71 & 79 & 4.13 \\
\hline
\end{tabular}
dicted number. As successive 20-day totals are correlated, mean and significance level of this test variable will be higher than with independence (van Montfort, 1966). By using the ordinary $\chi^{2}$ test, conclusions will be conservative. Results of

Table 2. Observed and expected occurrences of 20-day rainfall totals outside indicated limits. 
Table 3. Confidence limits for seasonal (or yearly) rainfall for 3 stations.

\begin{tabular}{|c|c|c|c|c|c|c|c|}
\hline \multirow[t]{2}{*}{ Station } & \multirow[t]{2}{*}{ Period } & \multirow{2}{*}{$\begin{array}{l}\text { Observation period } \\
\text { (years) }\end{array}$} & \multirow[t]{2}{*}{ Mean } & \multicolumn{2}{|l|}{$25 \%$} & \multicolumn{2}{|l|}{$10 \%$} \\
\hline & & & & upper & lower & upper & lower \\
\hline Guider & year & 37 & 934 & 1026 & 843 & 1110 & 759 \\
\hline Maroua & year & 25 & 808 & 890 & 726 & 965 & 650 \\
\hline Yaoundé & 1 Mar-7 July & 31 & 707 & 810 & 604 & 904 & 509 \\
\hline
\end{tabular}

the ordinary test for a number of stations in widely different climatic regions are presented in Table 2. Correspondence between observed and predicted numbers is excellent.

\section{Seasonal rainfall}

Confidence intervals of seasonal rainfall are given for three stations in Table 3. As skewness in all three cases was not significantly different from zero, no normalizing transformation was necessary.

\section{Frequency of dry spells}

A dry spell is defined here as a spell of a certain length with an average daily rainfall of les than some predetermined low value. Only dry spells longer than 10 days are considered. A dry spell which starts in a particular 20-day period and ends in one of the following periods is assigned to the former. Dry spell occurence was analysed for each of the 36 20-day periods for 3 stations, using a threshold value of $0.5 \mathrm{~mm}$ per day. Results are presented in Table 4 . The relationship between confidence limits for 20-day totals and dry spell occurence will be discussed in the next section.

\section{Application}

Application of this quantification of rainfall reliability runs as follows.

- Confidence limits for seasonal rainfall are used in order to gain a preliminary impression of the suitability of the climate for a specific crop.

- Confidence limits for rainfall in successive 20-day periods will give an indication of the earliest possible sowing date. Manning stated that in Uganda water is stored in the soil as soon as the mean daily rainfall exceeds $0.33 \mathrm{E}_{0}, \mathrm{E}_{\mathrm{o}}$ being the open water evaporation. He concluded that sowing was safe as soon as this base point was passed. Up to the present time no sufficiently accurate methods are available to estimate evaporation from a bare soil at different moisture contents. We will therefore continue using Manning's estimate of $0.33 \mathrm{E}_{\mathrm{o}} \mathrm{mm}$ per day. This is probably a lower limit and bare soil evaporation will be higher if rain falls in frequent small showers.

Caution, however, should be taken in estimating $\mathrm{E}_{0}$, especially under arid conditions: Penman's formula may seriously overestimate $\mathrm{E}_{0}$ under such conditions (Brutsaert \& Stricker, 1979). It is safer to use net radiation as the upper limit for open water evaporation for large areas. We arrive at some $5.0 \mathrm{~mm}$ per day for the 


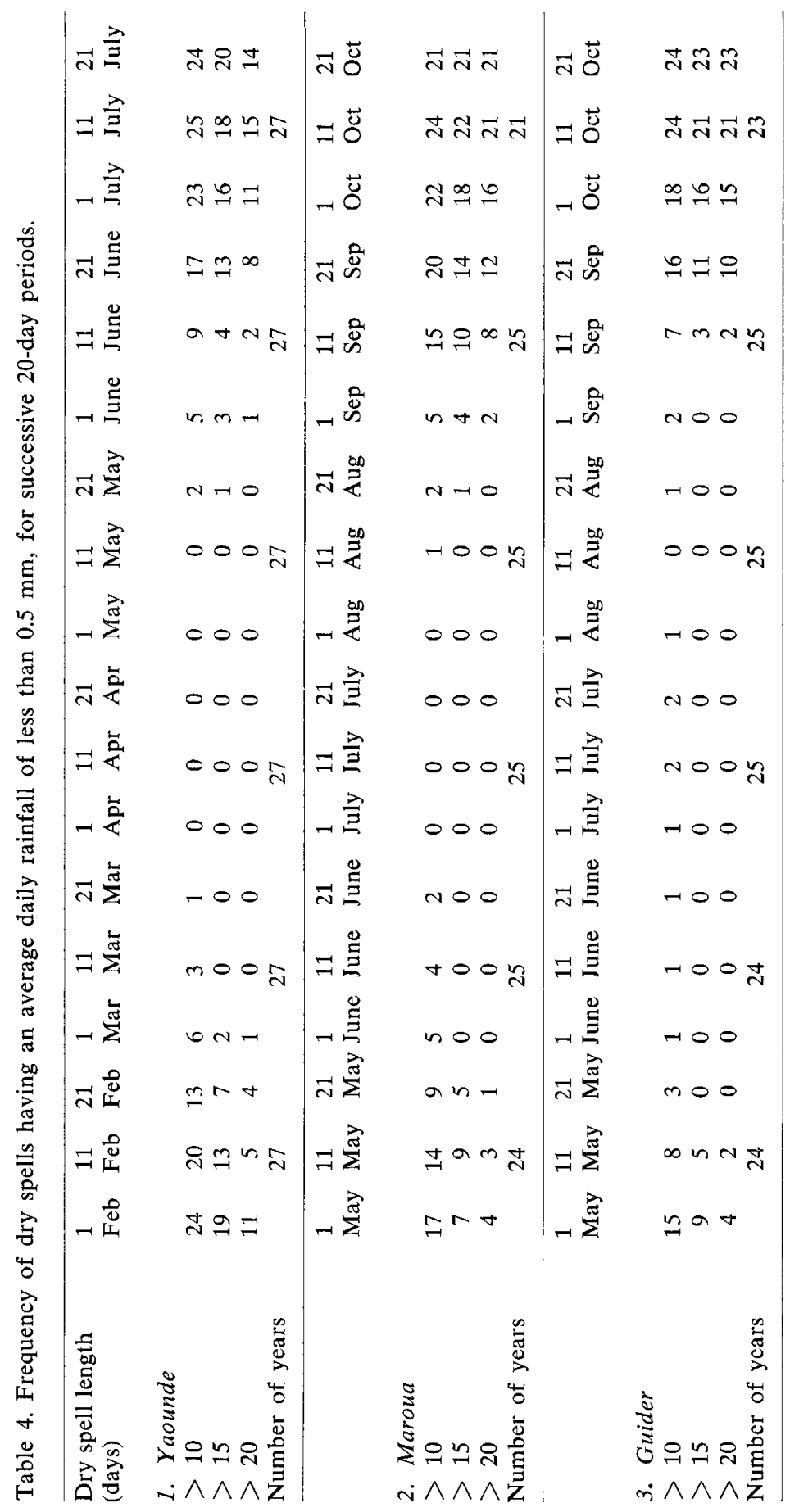


Yaoundé area and some $5.5 \mathrm{~mm}$ for Guider and Maroua for the periods considered below (radiation data from de Jong 1973).

- Frequency of dry spell occurence starting in a specific 20-day period serves as an indication of drought risk within each period. Germination and early development of seedlings are sensitive to moisture stress. Suppose that sowing is done as soon as the uppermost $20 \mathrm{~cm}$ of soil are wetted up to field capacity. The seed will then be able to absorb sufficient moisture for swelling and germination. As the soil dries out, the conditions for sowing deteriorate. The rate of drying of the soil depends on meteorological conditions and soil type. In the near future reliable computer programs will become available for calculation of the moisture changes in a profile subject to drying (e.g. Idso et al., 1979). The sensitivity of the seedling will depend on species and sowing depth. Simple field experiments would quickly yield results on the latter aspect. These additional data are necessary in order to set exact criteria for disastrous drought in the seedling stage of a crop.

As a preliminary, largely intuitive, figure for disastrous drought we adopt a dry spell (les than $0.5 \mathrm{~mm}$ average daily rainfall) of more than 10 days duration. Some crops are very sensitive to drought in specific stages of development, such as maize at tasseling. Depletion of available moisture below between $40 \%$ and $60 \%$, depending on soil type, during that stage will cause yield reduction (e.g. Vink et al., 1969). Dry spells of more than 10 days duration will, under most circumstances, probably cause such conditions to develop over $50 \mathrm{~cm}$ of profile depth (the main rooting zone of the crop).

- The two criteria (20-day total and dry spell occurence) may only be used if something can be said on their interrelationship. In order to assess this relationship the following approach is used. The numbers of the earliest period with rainfall exceeding $0.33 \mathrm{E}_{0}$ more often than once in four years and of the two succeeding periods were read from Fig. 2. For these periods the years with rainfall below 0.33 $\mathrm{E}_{\mathrm{o}} \mathrm{mm}$ per day and the years with dry spells exceeding 10 days duration were scored by computer from the daily rainfall record (years with more than one such dry spell starting in a period did not occur). For Guider, Maroua and Yaoundé around $45 \%$ of the years with a dry spell longer than 10 days also had a 20-day total below $20 \times 0.33 \mathrm{E}_{\mathrm{o}}$ in any of these periods. We may therefore state that, for the three periods considered, the joint probability of occurrence of either a 20-day period with less than $20 \times 0.33 \mathrm{E}_{0} \mathrm{~mm}(\mathrm{P}(\mathrm{A}))$ or a dry spell exceeding 10 days duration starting in that period $(\mathrm{P}(\mathrm{B}))$ or both, equals approximately

$$
\begin{array}{cl}
\mathrm{P}(\mathrm{AUB})= & \mathrm{P}(\mathrm{A})+\mathrm{P}(\mathrm{B})-0.45 \mathrm{P}(\mathrm{B}) \text {, or } \\
\mathrm{P}(\mathrm{AUB})= & \mathrm{P}(\mathrm{A})+0.55 \mathrm{P}(\mathrm{B}) \text {, with } \\
\mathrm{P}(\mathrm{A})=\text { probability of event } \mathrm{A} \\
\mathrm{P}(\mathrm{B})=\text { idem } \mathrm{B} \\
\mathrm{P}(\mathrm{AUB})=\text { joint probability. } \\
\mathrm{P}(\mathrm{B}) \text { is read from Table } 4 .
\end{array}
$$




\section{Examples}

Maize in the Yaoundé area

Pure maize stands give the best yields in the first rainy season (Bol Alima, personal communication). Total seasonal rainfall is largely sufficient for maize growing (Table 2).

As a lower limit for bare soil evaporation we use $0.33 \mathrm{E}_{0} \mathrm{~mm}$ per day, $\mathrm{E}_{0}$ being estimated at $5 \mathrm{~mm}$ per day. This results in a minimum requirement for a 20-day period of $33 \mathrm{~mm}$. In 3 out of 4 years this point is exceeded after 25 February and in 9 out of 10 years after 5 March (Fig. 2).

If we take dry spell occurence into consideration, sowing as soon as possible after 25 February is very risky: the joint probability of deficient rainfall for the two criteria would be in the order of

$0.25+0.55 \times 0.37 \approx 0.45$,

i.e. practically one event in every two years (dry spell frequency was 10 events in 27 years).

Sowing as soon as possible after 5 March would involve a risk of approximately

$0.1+0.55 \times 0.17 \approx 0.19$

or one failure every five years.

Maize being very sensitive to drought from tasseling to early ripening, this developmental stage should coincide with a period of reliable rainfall. This apparently is the case between 20 April and the end of May. Maize cultivars for the area should therefore typically have a 3 months growing period, tasseling starting after 1.5 months.

\section{Cotton in North Cameroon}

Both Maroua and Guider are in the cotton belt. Seasonal water requirements for optimum growth are in the order of $600 \mathrm{~mm}$ (cf. Manning, 1956). Yearly rainfall for both Guider and Maroua seems largely sufficient for cotton production (Table 2).

We estimated $E_{0}$ at $5.5 \mathrm{~mm}$ per day, resulting in a minimum requirement for a 20-day period of $36 \mathrm{~mm}$. In Maroua this point is exceeded in 3 out of 4 years after 20 May, in 9 out of 10 years after 15 June (Fig. 2). The joint probability of deficient rainfall for both criteria in the period after 20 May amounts to some $0.25+0.55 \times 0.375 \approx 0.45$

Sowing as soon as posible after 15 June involves a risk of approximately

$0.10+0.55 \times 0.12 \approx 0.17$ or one failure every 6 years.

In practice this risk is apparently considered too high, for in Maroua cotton is normally sown by the end of June. The period of highest transpiration demand of the crop (from three months after sowing) will then fall at the earliest in the 20-day period from 20 September. This is practically at the end of the rainy season and cotton is therefore a marginal crop for the Maroua area. This is apparently felt by the cotton authorities in Cameroon who are shifting the Northern limit of cotton growing to below Maroua, to conditions more adducive to reasonable yields. 
In the Guider area rainfall exceeds bare soil evaporation (estimated at $36 \mathrm{~mm}$ ) at the earliest in the 20-day period from 10 May onwards in 3 out of 4 years and in the period after 25 May in 9 out of 10 years. The joint probability gives

$0.25+0.55 \times 0.33 \approx 0.43$

for the period after 10 May and

$0.10+0.55 \times 0.08 \approx 0.14$

for the period after 25 May. Therefore sowing can be done almost one month earlier than in the Maroua area. Highest water demand would fall in the 20-day periods from 1 and 10 September. This is well within the rainy season.

\section{Discussion}

The present approach is an improvement of Manning's system of rainfall analysis. It uses both confidence intervals for 20-day rainfall totals and frequency of dry spell occurence. The motivation for this hybrid approach is that 20-day totals may be handled conveniently using simple statistical techniques, but they are insufficiently accurate to discover short term drought events. The approach may not be very satisfying to statisticians but the advantage is that the most relevant aspects of a rainfall record can be presented in a condensed and clear form: a figure and a table.

Calculations of confidence limits are more cumbersome than those needed for Manning's system, but the availability of computers makes this disadvantage of little importance.

Rainfall records of short duration could be analysed in the same way provided one has a station with a long record in the neighbourhood. The same transformation should be used as for the latter as the type of the distribution of both stations may be expected to be similar. As dry spell frequencies are less meaningful in such a case one has to rely on the 20-day totals alone and one should choose the $10 \%$ lower limit as a criterion. This criterion alone would result in a real risk for deficient rainfall in the critical sowing period of about once every 6 years.

\section{Note}

Results can be made available on any of the stations mentioned in Table 3. Requests should be directed to the author. The computer programs could be adapted for users if interest exists.

\section{Acknowledgments}

Thanks are due to $\mathrm{Mr} \mathrm{H}$. Stricker for his very helpful suggestions and criticism.

Dr. Bol Alima, Director of ENSA, University of Yaoundé is thanked for his permision to publish these results. 


\section{References}

Brutsaert, W. \& H. Stricker, 1979. An advection aridity approach to estimate actual evapotranspiration. Water Resources Res. (in press).

Hinkley, D., 1977. On quick choice of power transformation. Appl. Statist. 26: 67-69.

Idso, S. B., R. J. Reginato \& R. D. Jackson, 1979. Calculation of evaporation during the three stages of soil drying. Water Resources Res. (in press).

Jong, B. de, 1973. Net radiation received by a horizontal surface at the earth. Delft University Press, Delft, the Netherlands.

Langbein, W. B., 1960. Fitting curves to cyclic data. In: Manual of Hydrology. Part I. General surface-water techniques. U.S. Gorvernment Printing Office, Washintgon, D.C.

Manning, H. L., 1950. Calculation of confidence limits of monthly rainfall. J. agric. Sci., Camb. 40: 169-176.

Manning, H. L., 1956. The statistical assessment of rainfall probability and its application to Uganda agriculture. Proc. Roy. Soc. B 144: 460-480.

Montfort, M. A. J. van. 1966. Statistische beschouwingen over neerslag en afvoer. Veenman, Wageningen.

Searcy, J. K. \& C. H. Hardison, 1960. Double-mass curves. In: Manual of hydrology. Part I. General surface-water techniques. U.S. Government Printing Office, Washington, D.C.

Smith, R. E. \& H. A. Schreiber, 1973. Point processes of seasonal thunderstorm rainfall. 1. Distribution of rainfall events. Water Resources Res. 9 (4) 871-884.

Smith, R. E. \& H. A. Schreiber, 1974. Point processes of seasonal thunderstorm rainfall. 2. Rainfall depth probabilities. Water Resources Res. 10 (3) 418-423.

Snedecor, G. W. \& W. G. Cochran, 1967. Statistical methods. The Iowa Univesity Press, Ames, Iowa.

Vink, N. H., A. Aboukhaled \& S. Sarraf. 1969. Evapotranspiration and yield of corn in the Central Bekaa, with special reference to the effect of advection. Magon, Institut de Recherche Agronomique du Liban, Série Scientifique No 29. 